SYMBOLIC REPRESENTATION OF SECURITIES TRADE SETTLEMENT MESSAGES APPLYING THE PRINCIPLES OF FORMAL LANGUAGES FOR BUSINESS COMMUNICATION

by

Mark Ginsburg

Steven 0. Kimbrough

Bruce weber 


\title{
SYMBOLIC REPRESENTATION OF SECURITIES TRADE SETTLEMENT MESSAGES APPLYING THE PRINCIPLES OF FORMAL LANGUAGES FOR BUSINESS COMMUNICATION
}

\author{
Mark Ginsburg \\ Stern School of Business \\ New York University \\ Steven 0. Kimbrough \\ University of Pennsylvania \\ Bruce w. Weber \\ Stern School of Business \\ New York University
}

Working Paper series

STERN IS-93-45 


\title{
Symbolic Representation of Securities Trade Settlement Messages Applying the Principles of Formal Languages for Business Communication
}

\author{
Mark Ginsburg*, Steven O. Kimbrough**, and Bruce W. Weber* \\ New York University (*) and University of Pennsylvania (**)
}

\begin{abstract}
The increased use of network communications within industries, and among firms, suppliers, and customers, is focusing greater attention on the methods and standards for interorganizational communications. In the securities industry, the settlement and clearing of trades depends on numerous messages to be sent and received by several organizations. Using the principles of Formal Languages for Business Communication (FLBC), we develop a message representation that is flexible and selfdescribing, and show how defeasible reasoning applied to settlement messages could handle problem trades. This application of FLBC offers advantages through machine-to-machine error reconcilement, integration with other market communications systems, and robustness to changes in securities design and regulation.
\end{abstract}

\section{Introduction}

Close to one million securities trades take place daily on U.S. stock exchanges and bond markets. The clearing of these transactions involves the matching of buyers' and sellers' submitted trade reports, and the confirming the indicated trades. The settlement of these transactions is the process of transferring ownership from the seller to the buyer, and of delivering payment from the buyer to the seller. Settling and clearing a trade requires a number of messages to pass between the two trading parties (generally, investors or securities firms), and their brokers and custodial trust agents, and the clearing houses and depositories. These organizations and their functions are described in Table 1.

Settlement and clearing is a high-volume information processing function. Currently, different message formats are used in different markets, and details of a single trade may be entered several times into different systems. Messages use fixed field formats, which are not easily adapted to new securities or conditions. Exceptions reports from the clearinghouse that are transmitted back to the trading firms provide limited help resolving problem trades. This paper describes a formal language representation for trade messages that could eventually support a single financial transaction messaging system to be used by banks, securities firms, institutional investors, and other parties associated with global trading. The representation uses a flexible and self-describing message syntax, and defeasible reasoning for back-end exceptions processing. We demonstrate the applicability of formal business communication principles to enable reasoning about the content of inter-organizational messages, and we describe potential benefits.

Present arrangements for message handling are wellsuited to standard trade settlement activities, and have proven capable of handling severe peaks in volume. The settlement process was not interrupted at the time of the stock market break on 19 and 20 October 1987, when 604 and 608 million shares, or more than triple the average daily volume at the time, were traded on the New York Stock Exchange [LUCA89]. Since 1987, capacity has been put in place to handle a one billion share day. However, current settlement systems are less capable of handling non-routine events such as resolving unmatched trades, and facilitating settlement of new types of securities. In about 1 percent of all stock market trades, and between 20 percent and 30 percent of bond trades, the settlement message returned to the trading parties is "uncompared as submitted." On the New York Stock Exchange, about 5,000 submitted trade reports a day do not lead to a match between the buyer's account of the trade details and the seller's version. When an uncompared trade often called a DK for "don't know" or QT for "questioned trade" occurs the parties involved will normally need to contact each other manually to resolve the reports. They will then resubmit corrected versions of the trade details, or submit a reversal of the trade, in effect canceling it.

Across the eight financial markets in the U.S. that clear trades through the National Securities Clearing Corporation, nearly 15,000 submitted trade reports a day are uncompared. At approximately $\$ \mathbf{5 7 5}$ per item to resolve a problem, the annual cost of exceptions processing is $\$ 250$ million. Uncompared or open trades (that may not eventually be settled) also expose firms to price movements that may make completing the trade more expensive than anticipated. Adding a new security type, such as a bond with a detachable option, requires developing a new record format for both input and output to

To Appear: Proceedings, 27th Annual Hawaii International Conference on Systems Sciences, Maui, Hawaii, January, 1994. 
the settlement system. Added strain will come from the replacement of the current five day settlement cycle with three day settlement, which is mandated to occur in the U.S. before 1996.

Global initiatives. In 1989, the Group of 30 (G30), an independent non-profit organization of managers and representatives of financial institutions from 30 nations began to promote greater harmonization of settlement systems internationally. The G30 found that "present standards were not acceptable", and set out nine longterm goals for "maximizing the efficiency and reducing the costs of clearance and settlement." Two goals are uniform, three-day $(T+3)$ rolling settlement, and sameday settlement payments in all markets. A 3-day settlement cycle will reduce the replacement cost risk of outstanding trading commitments that would need to be covered if a default occurred. Same-day funds lessens the credit exposure from outstanding payments due from buyers of securities. Meeting the G30 objectives and enhancing settlement systems requires better software that permits richer information processing, in particular, faster comparison and reconcilement of uncompared trades.

Benefits of enhanced settlement messaging. This paper will detail a representation for inter-organizational messages that enables greater integration of front- and back-office systems, and richer expression of settlement messages. A better representation scheme will improve the process of resolving mismatches, and will enable trading in new securities to be processed without designing additional, customized message formats. With the added capabilities that we describe, trade exceptions will increasingly be resolved via CPU-CPU conversations.

\section{TABLE 1: GLOSSARY}

BROKER: An agent representing an investor that wants to buy or sell securities in a marketplace.

aEArINCHOUS: Clearinghouses guarantee the completion of trades submitted by their member firms. Once a trade is matched and accepted, the clearinghouse becomes the counterparty to both sides of the trade, which limits the credit risk of defaults on trades due to a bankruptcy. In the U.S. there are three clearinghouses and three depositories for the country's seven stock exchanges and OTC equities market. There are nine clearinghouses for the fourteen futures exchanges, and one clearinghouse for the options exchanges. The largest U.S. clearinghouse is the National Securities Clearing Corporation (NSCC).

custoouv: Banks and securities firms provide custody services to investors. A custodian is an agent that makes and receives payments for securities and provides safekeeping of certificates them for investors.

DEPOSITORY: Securities depositories store certificates, and oversee book-entry transfers of ownership. Depositories and clearinghouses are the two principal clearing organizations. The largest U.S. depository is the Depository Trust Company (DTC).

\section{Current Messaging Practices}

Settlement and clearing is achieved through a complex web of communications between brokers, custodians, clearinghouses, and depositories sending electronic and non-electronic messages. Existing messaging systems automate earlier paper-based procedures. The messages are based on fixed field formatting with little flexibility, and limited expressive power.

Trading communication. The operations cycle for a standard trade involving two investors can result in as many as ten messages. (We refer here to an institutional investor, such as a mutual fund or a pension fund manager, rather than an individual investor. For an individual, the settlement process is completely handled by the broker acting on their client's behalf.) (1) To maintain a diversified portfolio or to raise cash or invest cash an investor, who has decided to sell a security, phones his or her broker to request a quote or place a sell order. (2) The broker sends execution instructions to a trader who finds a counterparty (or, counterparties) in the market at an agreed upon price and quantity. An order form is partially written out by the broker, and given to the trader. It contains the customer's instructions, and is completed by the trader after executing the order. Figure 1 shows the typical Order Form.

At the end of the day, (3) the brokers report the details of their "sides" of all executed trades to the clearinghouse. (4) The clearinghouse compares all submitted trade details, and reports back the matched and unmatched trades to traders (QTs or questioned trades, when the parties do not agree on details, and DKs or don't knows, when only side of a trade is reported). (5) The broker confirms the trade to the investor and to the investor's custodian. (6) The investor "affirms" the transaction to the broker, indicating that on settlement date, shares are to be received into the broker's account from the clearinghouse account, in the case of a purchase, or, in the case of a sale, delivered to the clearinghouse account from the broker's account.

The clearinghouse nets all transactions (7), and sends net obligation notices (to deliver shares/cash and receive shares/cash) to members. (8) The clearinghouse initiates the transfer of shares into the buying broker's account at the clearinghouse. (9) The buying broker (who is in a net debit position) then instructs the bank to pay funds into the clearinghouse account, at which point the securities transfer becomes final. If either the securities are not delivered, or the payment is not received, the trade "fails". Failed trades are liabilities of the non- 
Figure 1: Typical Order Form

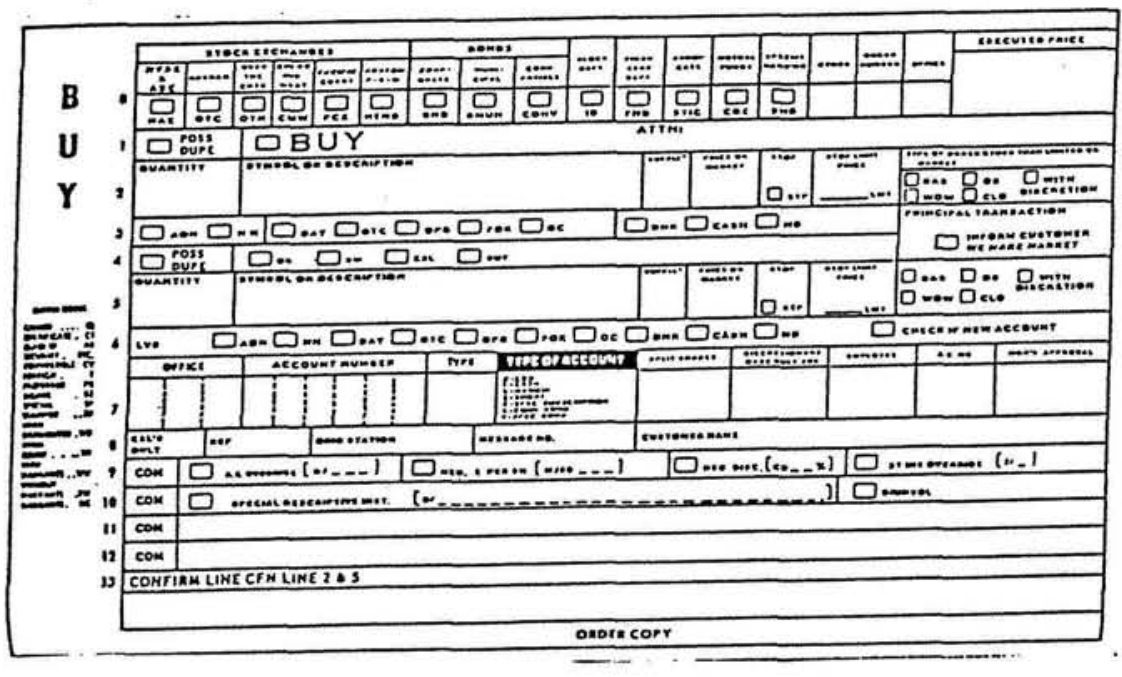

Clearinghouse operations. Clearinghouses are hubs for settlement instructions and communications between market participants. The largest U.S. clearinghouse is the National Securities Clearing Corporation (NSCC). The NSCC was formed in 1977 by merging the clearinghouses of the New York and American Stock Exchanges, and the over-the-counter market. The NSCC has links with 1,200 direct participants, and processed over 90 percent of all equities trades in the U.S. in 1991.

Currently, the settlement cycle the time between a trade and the final transfer of payment and securities ownership is five days in the U.S. In the U.K. and France, settlement periods are as long as 3 to 4 weeks (Weber, 1993). Participants in a trade are required to submit trade reports to the NSCC by midnight on the day of the trade $(T)$. In the early morning

delivering party, and result in fees, interest, and borrowing charges. (10) The clearinghouse pays into the account of the selling broker. Note that all but steps (8) and (10) are inter-organizational instructions.

\section{Figure 2}

Steps \#1 to \#6: Order entry through investor affirmation

\section{(Trade Execution)}

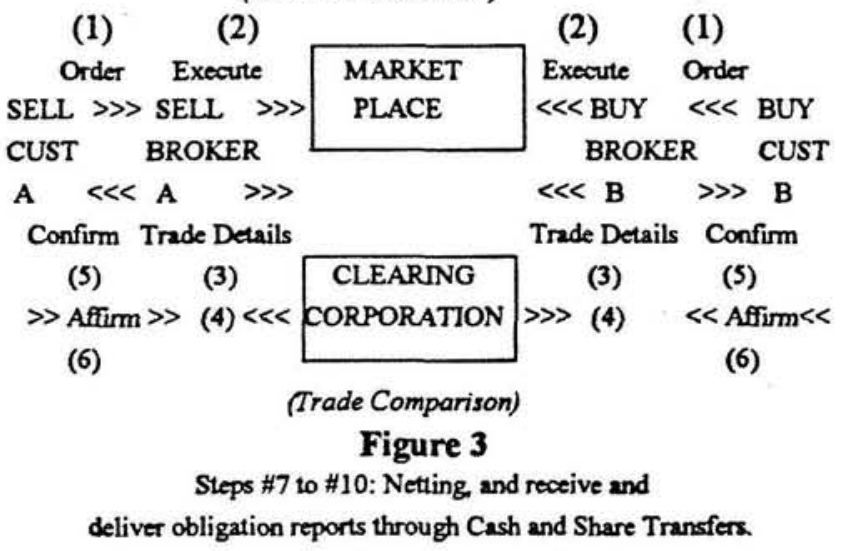

\begin{tabular}{|c|c|c|c|c|c|c|}
\hline $\begin{array}{l}\text { SELL } \\
\text { CUST }\end{array}$ & SELI & & & & $\begin{array}{l}\text { BUY } \\
\text { RROKER }\end{array}$ & $\begin{array}{l}\text { BUY } \\
\text { CUST }\end{array}$ \\
\hline & $\mathbf{A}$ & $\ll$ & & \multirow{2}{*}{\multicolumn{3}{|c|}{$\begin{array}{c}\gg \text { B } \\
\text { Obligations }\end{array}$}} \\
\hline & & \multicolumn{2}{|c|}{ Obligations } & & & \\
\hline & & (7) & \begin{tabular}{l|} 
CLEARING \\
CORPORATION
\end{tabular} & \multicolumn{3}{|c|}{ (7) } \\
\hline \multicolumn{3}{|c|}{ 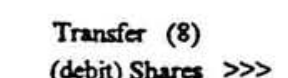 } & (Netting) & \multicolumn{3}{|c|}{ 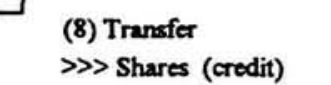 } \\
\hline (credit) & it) Cest & $\ll$ & (10) & \multicolumn{3}{|c|}{$\ll<$ Cash $(9)$ (debit) } \\
\hline
\end{tabular}

hours of T+1, the NSCC "compares" all submitted trades "sides." Each trade has two sides, a buyer side and a seller side. The comparison procedure establishes matches between submitted sides. If a trader submits the details of a purchase of 5000 shares at $\$ 40$ from a broker with badge number 123-789, there needs to be an offsetting entry to sell 5000 shares at $\$ 40$ from the broker with badge number 123-789. Once a match is made the obligations of the original counterparties are to the NSCC, rather than to each other. The seller delivers or transfers securities into an NSCC account at the depository, and receives payment from the NSCC. By backing trades only once they have compared, NSCC has a zero net position in funds and in shares; i.e. the funds receivable by the clearinghouse are exactly equal to its funds payable, and their securities deliverable equals their securities receivable. By standing between the ultimate buyer and seller, the NSCC eliminates "counterparty risk" in the market, or the chance of losses caused by one party to a trade defaulting on its obligations.

Uncompared trades are sent back to the original marketplace on $\mathrm{T}+1$ for resolution by the trading parties. Securities firms' Purchase and Sales (P\&S) departments receive contract sheets from the clearinghouse with compared and uncompared transactions listed. To resolve uncompareds, trading tickets and records are often examined to find the source of any error. Compared trades that were only "suggested" by the NSCC's matching program (because one or more of their fields may have differed), may be rejected and reversed. Only if trading parties can correct the discrepancy and resubmit the 
details for a matching by the end of the third day after the trade $(\mathrm{T}+3)$ will the settlement occur in its original place on $T+5$. The NSCC nets all securities and funds due it on settlement day, and during the night of $T+4$ instructs the DTC to transfer ownership of the traded securities. The transfer is made provisionally on the morning of $T+5$. If the securities are not in the selling firm's DTC account, it has until 1:30 p.m. on $T+5$ to supply them to the DTC. At 3:00 p.m., the NSCC notifies each counterparty of its net funds liability. Once members with debit funds positions make payment, their incoming securities transfers (credits) are final. This payment must be made by 7:00 p.m. on $T+5$, and is via a clearing bank check or wire transfers into NSCC accounts.

Clearinghouse messages and systems. To compare trades in a particular financial instrument (listed stocks, over-the-counter stocks, bonds, etc.), one message per trade side is electronically submitted to the NSCC. The NSCC puts submitted trade reports into its Continuous Net Settlement (CNS) system, a comparison system that runs as a batch process in the early hours of $T+1$. The comparison algorithm seeks to match trades by finding submitted reports from a buyer and a seller for the same security reporting the same prices and number of shares traded. The results of the comparison for each input are transmitted back to the securities firms as output.

The Trade Detail Input and Corrections message reports one side's account of the trade. The record consists of two 80-column rows comprising 15 fields. The principal elements (not complete) of the record structure are indicated in Figure 4.

The Trade Output and Adjustment message is three 132-column records that describe the results of the comparison. The output consists of 15 fields. Its main features are the NSCC-assigned control number (a unique identifier for each trade), and a trade status code reporting whether the trade compared or not. If there was an exact comparison between the trade details submitted by the buyer and the seller, the status codes are "A1", "S1", or "P1". If the match is inexact, there are 16 other codes indicating the disparity. The reasons for an inexact match include reported badge numbers that differ from the actual, and differences in the reported times of trade execution. There are 3 codes for uncompared trades: "U1", "U2", and "SA". The principal elements of the message structure are shown in Figure 5.

Although NSCC operations use computer-tocomputer links, the participant brokerage houses do not have any knowledge of the relationship between the qualifiers in the output report. Thus, an uncompared trade requires manual exceptions processing, and perhaps telephone calls to other brokerage firms. Enhancements to the message representation will enable the firms to better identify the causes of a mismatch by developing interpretation rules to correct it automatically.

Pressures for enhancements. Two environmental factors call for enhanced, and more flexible clearing operations.

1) Economic and regulatory pressures are growing for the standardization of data and procedures to eliminate or greatly reduce national differences.

2) Communications and the technology of the backoffice are becoming commodities but inflexible messaging limits integration across shared networks, and nonproprietary systems from multiple vendors.

In the Market Reform Act of 1990, the U.S. Congress directed the Securities and Exchange Commission to "facilitate the establishment of linked or coordinated facilities for clearance and settlement of transactions in securities."

Given the external pressures, current clearing systems will be hard pressed to accommodate the necessary changes. Substantial improvement, we argue, will come from a better message representation. We envision more expressive messages being transmitted back and forth between the firms and the clearinghouse, and brokerage firms' implementation of rule-based policies that offer greater opportunities for computer-computer reconcilement of problem trades. Uncompared trades and inexact matches will still be handled by each firm's idiosyncratic methods.

\section{Recursively-defined Settlement Messages}

As electronic business communications grow, researchers are seeking better methods for expressing interorganizational communications (Kimbrough and Moore, 1992). A goal of inter-organizational communications is to represent messages symbolically so that they can be interpreted electronically. Once received, a well-designed representation will enable the receiver to access its meaning and act on it, with little or no human intervention. Logical inferencing and defeasible reasoning can be applied in order to initiate and complete tasks based on the transmitted information. We adapt the notation of Kimbrough and Moore (1993) to the securities trading domain:

Op(who, what) where who is the double consisting of the executing broker and the contraparty to the trade identified by their firm and their badge number leg. whol(merrill, badge_no),(pru_bache,badge_no))], and what is a description of the transaction.

The operators relevant to securities trading include (but are not limited to) the following predicates: 
Figure 4: The Irade Detail Input and Corrections Report

\begin{tabular}{|c|c|c|c|c|c|}
\hline FELD NAME & LENGTH & START & END & TYPE & COMUIENTS \\
\hline BUY/SELL IND. & 1 & 3 & 3 & $\mathrm{ANN}$ & $2=B \cup Y, 4=S E L L$ \\
\hline T+1 REGULAR WAY & 1 & 4 & 4 & $\mathbf{N}$ & $\begin{array}{l}1=T+\text { REGULAR WAY } \\
D=D E L E T E \text { OF ORIGINAL } T+1 \text { INPUT }\end{array}$ \\
\hline BROKER NUMBER & 4 & 6 & 9 & $\mathrm{~N}$ & MAJOR BROKER NUMBER (NO SYMBOL) \\
\hline EXEC BADGE & 4 & 10 & 13 & ANN & EXECUTING BADGE NUMBER \\
\hline CONTRA EXEC BADGE & 4 & 18 & 21 & AN & CONTRA EXECUTING BROKER BADGE \\
\hline TRADE DATE & 6 & 22 & 27 & $\mathrm{~N}$ & (MMDDM \\
\hline CUSIP NUMBER & 9 & 28 & 36 & AN & \\
\hline EXCHANGE IND. & 1 & 39 & 39 & $\mathrm{~N}$ & $0=$ NYSE, $1=$ AMEX, $2=$ OTC, $3=$ OTHER \\
\hline QUANTITY & 8 & 40 & 47 & $\mathrm{~N}$ & $(99,999,999)$ \\
\hline CONTRACT AMOUNT & 12 & 48 & 59 & $\mathrm{~N}$ & $(9,999,999,999.99)$ \\
\hline TIME OF EXECUTION & 4 & 63 & 66 & $N$ & HHMM (MILITARY TIME) \\
\hline
\end{tabular}

Figure 5: The Trade Output and Adjustment Record Format

\begin{tabular}{|c|c|c|c|c|c|}
\hline FELD NAME & LEN & START & END & TYPF & CONTMENTS \\
\hline BUY/SELL IND. & 1 & 1 & 1 & $\mathrm{ANN}$ & $2=\mathrm{BUY}, 4=\mathrm{SELL}$ \\
\hline $\begin{array}{l}\text { ACCEPT/REJECT } \\
\text { IND. }\end{array}$ & 1 & 2 & 2 & AN & $\begin{array}{l}\text { 0=ACCEPTED, } 1=\text { INVALID BUY/SELL OR } \\
\text { ACTIVITY CODE, } 2=\text { INVALID TRADE } \\
\text { DATE, } 3=\text { INVALID CUSIP NUMBER, } 4= \\
\text { INVALID QUANTITY OR CONTRACT } \\
\text { AMOUNT, } 5=\text { INVALID TRANSACTION } \\
\text { TYPE, } 6=\text { INVALID DELETE, } 8= \\
\text { MULTIPLE ERRORS }\end{array}$ \\
\hline CONTROL NO. & 10 & 85 & 94 & $\mathrm{AN}$ & CONTROL NUMBER \\
\hline $\begin{array}{l}\text { TRADE STATUS } \\
\text { CODE }\end{array}$ & 2 & 95 & 96 & $\mathrm{AN}$ & $\begin{array}{l}\text { A1 = EXACT MATCH USING BADGES } \\
\text { AND TIME A2 = EXACT MATCH USING } \\
\text { BADGES AND DISREGARDING TIME } \\
\text { A3= EXACT MATCH USING ONE SET OF } \\
\text { BADGES AND TIME A4= EXACT MATCH } \\
\text { USING ONE SET OF BADGES AND } \\
\text { DISREGARDING TIME A5 = EXACT } \\
\text { MATCH USING TIME DISREGARDING } \\
\text { BADGES S1-S5= PIECES SUMMARIZED } \\
\text { MATCH USING A1-A5 CRITERIA P1-P5 = } \\
\text { MATCH USING PIECES AUDIT TRAIL } \\
\text { CRITERIA: MI-M4 U1= UNCOMPARED } \\
\text { AS SUBMITTED U2= UNCOMPARED AS } \\
\text { A RESULT OF SUMMARIZATION SA = } \\
\text { SUBMITTED ADVISORY AGAINST YOU }\end{array}$ \\
\hline
\end{tabular}




\section{Op $\in$ (submitted,compared,confirmed, deleted, af-} firmed, obligated, delivered, received)

These operators apply to transactions, which are defined by the following descriptors: security, date, rate,value, quantity, price. These descriptors consist of a number of arguents, and can be of arbitrary length. Thus, new instruments can be incorporated by adding additional arguments. The security traded and its description is represented with four arguments by:

security(certificate_no, when_issued, country, exchange). For a U.S. security the certificate number will be its CUSIP code. A trade date and time is associated with each trade: date(trade,time_of_exec) We show later that using rules, the settlement date can be inferred from the trade date and the status of the trade comparison. Rates are the proportional values that apply to a transaction: rate(currency,tax,commission) The currency is the money to be used to settle the trade. The commission and tax are applied to the contract value of the trade. Values are the amounts that apply to the transaction, and their description is represented with four arguments by: value(contract_amount, accrued_interest, commission_amount, tax_amount). Quantities are usually the number of shares, but with a qualifier can be expressed as units or lots. Quantities to buy or bought are positive, and quantities to sell are negative:

quantity $(Y)$ where $Y \in$ (shares,units,lots). Price are indicative, or firm, or contractual: $\operatorname{price}(Y)$ where $Y \in$ (indicative, quoted, executed). Many of these could be entered at a trading desk, using a real-time deal capture system. Although some are mandatory, not all qualifiers need to be specified.

Example. A standard trade message could be:

submit((merrill,1234), (pru_bache,7890)), security(cusip(869267BN3),reg_way,us,nyse), date $(930621,150333)$, rate(usd, $0.0015,0$ ), value(426250.00, 0, Commission_amount, Tax_amount), quantity(shares(5000)), price(executed(85.25))).

This depicts a purchase of Allied-Signal (CUSIP No. $869267 \mathrm{BN} 3$ ) by Merrill Lynch broker \#1234 of 5,000

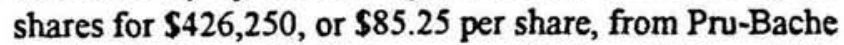
broker \#7890 at 3:03:33 p.m. on 21 June 1993. (This message contains propositional content, and for present purposes, and without loss of generality, we are neglecting the speech-act aspects of these messages.) At the time of submission, the transaction is provisional. It becomes contractual or obligatory when it is successfully compared with a contraparty trade report. The trade is settled when ownership and payment have transferred.
We envision three capabilities of an industry-ride formal language for trade clearing and settlement: (1) generation of informative messages from the clearinghouse identifying problem trades, (2) broker-initiated messages that will be sent to the clearinghouse and other brokers to resolve problems, and (3) application of defeasible reasoning to the messages a firm receives in order to understand its financial exposure, and to take actions such as deleting a transaction from a database of trades. We focus on the first capability in this paper, and refer later to the benefits from the other two.

Rules: Once submitted, a transaction has a control number, $\mathrm{X}$, assigned to it. The system increments $\mathrm{X}$ once after each arrival. We assign a unique control number that follows from the prior transaction. (Note that we use declarative, Prolog rules for expositional convenience. The operations described could be in a procedural language.)

submit $(S, D, R, V, Q, P, X) \leftarrow$ submit $(S, D, R, V, Q, P)$, current_transaction( $W$ ), next_transaction $(X, W)$.

Current_transaction is only satisfied by the most recently processed trade report. The predicate, next_transaction assigns to $\mathrm{X}$ the next control number following $\mathrm{W}$. Thereafter, every transaction can be identified by its control number: transaction $(X) \leftarrow$ submit $(ג, d, X)$. A set of rules contained in a knowledge base determines the result of the comparison process for each transaction. Two transactions, $X$ and $Y$ compare exactly if their submission reports indicate they are for the same security (S), traded the same day and time (D), using the same currency $(B)$, for the same contract amount and accrued interest $(\mathrm{V})$, and their quantities $(\mathrm{Q})$ and prices $(\mathrm{B})$ match. Note that the signs of quantity traded are reversed to ensure that one and only one party reported itself to be the buyer (positive quantity), and one and only one party reported itself to be the seller (negative quantity). An exact match is an "Al" code in the current comparison output.

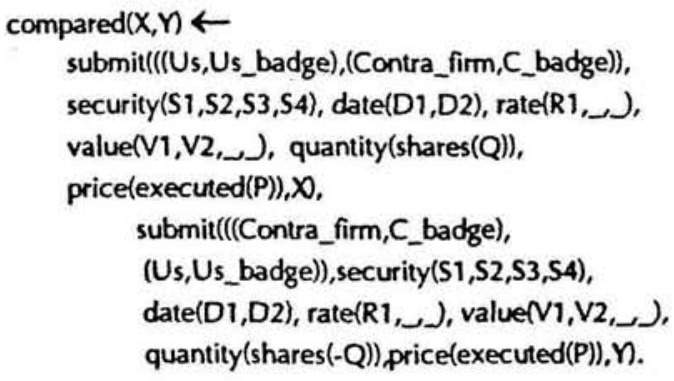

Any transaction, $\mathrm{X}$, is compared if it compared with any other transaction, but only one other transaction. 
compared $(X) \leftarrow \operatorname{compared}(X, Y)$. not(compared $(X, Z)), \operatorname{not}(X=Z)$.

Defeasibility. The submission of trade details does not necessarily lead to contracted trades. Inexact comparisons are possible, and can be reversed by the trading parties. In fact, only 53 percent of the NYSE's compared trades are exact matches: i.e., yields "A1", "P1", or "S1" in the Comparison Code field in the NSCC output report. The others match on the security, price, and size of the trade, but have discrepancies in the reported badge numbers, or the time of the trade. In some cases, these inexact matches are invalid, and the two firms involved will "reverse" the trade. In our representation, two trade reports will match with different trade times if the following rule is satisfied. This corresponds to an A2 match in the existing NSCC output report. Notice here that the two reported times are returned to the brokerage firms for their auditing. There are about $9,000 \mathrm{~A} 2$ match reports daily on the NYSE:

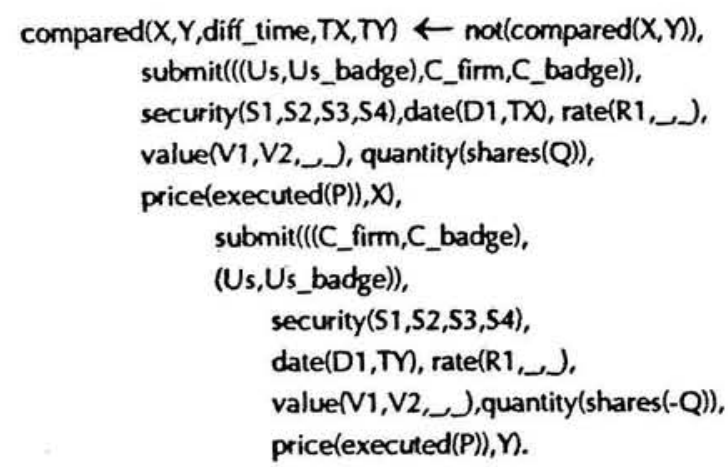

Two trade reports that misidentify the contraparty, but match on the time of the trade will match if the following rule is satisfied. This corresponds to an A5 match in the existing NSCC output report. About 8 percent of the daily 130,000 comparison outputs on the NYSE are A5 matches.

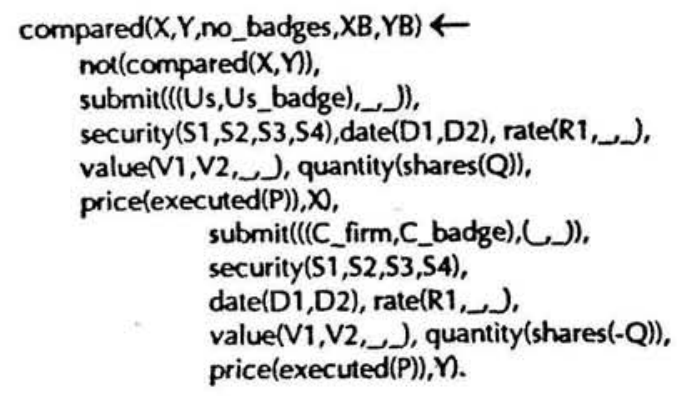

With the additional expressiveness of a recursive syntax, more comparison information can be supplied to the brokerage firms. Using these rules, trades will either have an exact comparison, an inexact comparison, or no comparison. No comparison can be inferred:

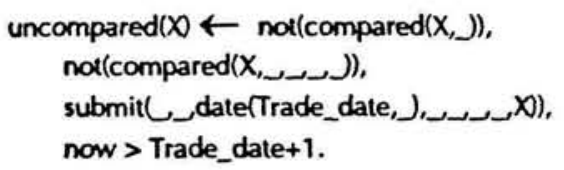

Also, in Prolog, we can list all of the reasons for an inexact comparison of the transaction with control number $\mathrm{X}$ :

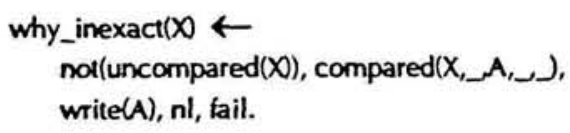

This constitutes a major improvement over current practice, which only reports a code e.g., "P4" but no additional output for auditing possible (but unlikely) erroneous matches. Using a self-defining syntax, trades that have inexact comparisons (e.g. same price and quantity, but different badges or times reported), will be reported with the details of the discrepancies to enable the brokerage firm to ensure that the trade really should be compared, and passed through for settlement.

The current clearing and messaging system could probably be enhanced to provided more output detail, and to add many of the capabilities described. Such modifications would be difficult, and would require major changes to message formats, and large-scale alterations to the structure of brokerage firms' software. The approach we describe, however, enables changes to be made easily at the level of software modules, and at low cost. The example programs illustrate the simplicity of capturing and returning valuable information to the trading parties. As new rules and conditions are conceived, they can be implemented easily.

Rules can also express time, obligations, and the defeasibility of interim assumptions. Transactions that are obligatory or contracted can be reflected in the firm's financial reports.

Time. A transaction may be either provisional, contractual, or settled depending on the time it was submitted, and its status in the clearing process. The system clock-calendar increments 1 for each weekday that the market is open. For a compared trade, the settlement date is five days after the trade date.

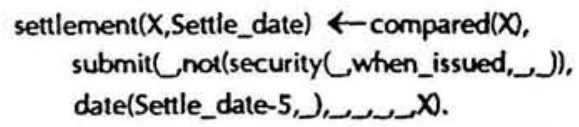

Thus, Settle_date for the transaction with control number $\mathrm{X}$ will be designated the trade date plus five, if the transaction compared. 
Contingent on external variables such as time, rules will perform defeasible reasoning on the messages a trading firm receives from other firms and the clearinghouse. Rules of obligation and defeasibility will provide inferencing capabilities within firms' clearing systems.

Reasoning on messages. Three operators can be defined to apply to trading messages that a firm receives. The first is obligation: $Q \phi$ means it is obligatory that $\phi$. Povisionally (or defeasibly) $\phi$ is $\rho \phi$. When conflicts $\alpha$ cur, any fact can be undermined U. Transactions are provisional until they are successfully compared, at which time they become obligatory. "Now" is the current value of the system clock-calendar, and by convention will increment 1 for each day.

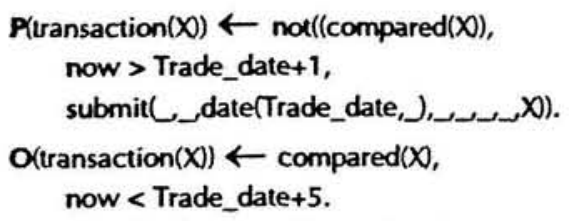

We envision brokerage firms implementing systems that maintain default hierarchies of rules to handle conflicting obligations. (See Kimbrough and Moore (1993) for a discussion of conflicting obligation.)

Currently, submitted trade reports that differ on the price or security ID (CUSIP) or quantity of a trade do not compare, and are reported only as uncompared without indications of any identifiable causes for the mismatch. By providing additional information along with a transaction's uncompared output, brokerage firms can resolve uncompared trades using defeasible rules.

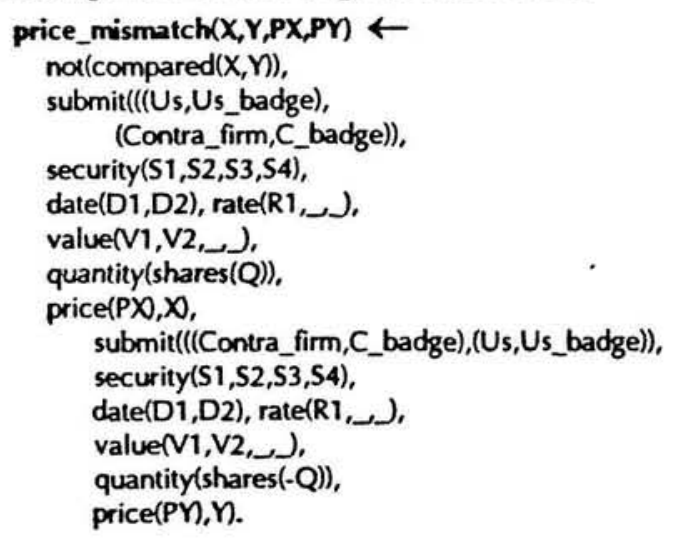

The predicate price_mismatch( $\bullet$ ) reports the contrabroker who submitted a near-matching trade with a price, PY, that differed from the other reported price, PX. For differences less than some fraction of a percent, brokerage firms could agree to randomly select one of the submitted prices. Similarly, a quantity mismatch can be defined, and presented to user firms along with a report of the two different reported quantities. Minor quantity differences could be resolved by "splitting the difference" or alternating which quantity is used. More advanced clearing networks could lead to cross-organizational rules that access to other firms' messages. For instance, if a firm's broker submits a trade report that matches an machine-readable order of another firm, it indicates the likely source of the problem is the other firm's submitted trade report.

\section{Discussion}

Let us catalog our progress. We have reviewed the securities trade settlement process, and found it to be message-intensive, costly, and time-consuming. To ameliorate these problems, we have following suggestions in the literature (e.g., Kimbrough and Moore, 1992 and 1993) proposed an application of an FLBC. In the present context, this proposal has two main parts. First, much greater reliance should be made on formalized, computer-to-computer messaging, as opposed to nonformal, person-to-person messaging (e.g., telephone calls). The current system relies on formal messaging only in part (see Figures 4 and 5), and could benefit by extending formal messaging to communications between a brokerage firm and its traders, and among brokerage firms. Second, the FLBC to be used should be a recursively-defined, open-ended language, similar to that illustrated in the discussion above.

We have, in addition, offered examples of trade processing messages, and how they could be used and interpreted. More examples could be given, but space is limited and we believe the point has plausibly been made that the FLBC approach can readily handle all of the types of messages now used, plus offer the additional information for resolving problem trades. We now list, and briefly discuss, the principal advantages of the general approach we are advocating for handling securities trade settlements.

Faster responses to uncompared trades will support the transition from a 5-day to a 3-day settlement crcle. As discussed above, if the settlement cycle is to be reduced from 5 to 3 days, then it is imperative that uncompared trades be resolved much more quickly. Introducing further formalization of the messaging process especially among brokers attempting to resolve uncompared trades is really the only practicable way to effect deeper computerization and with it greater speed in this process. Further, given that further formalization will occur, use of a well-designed, general-purpose FLBC, as discussed here and in (Kimbrough and Thornburg, 1989, and Kimbrough and Moore, 1992, 1993), has much to recommend it, as the following points will indicate. 
The representation method is able to integrate new information and securities types without adding new message formats or standards. The language structure remains fixed, but is able to accommodate new vocabulary terms and to express an unlimited number of messages. This allows the contents of the messages to adapt to new business requirements. While the messages may evolve, there is no undue disruption to the systems handling them (see Kimbrough and Moore, 1992).

Problem trades may be more easily reconciled, because brokers can be provided with more useful details from the clearinghouse comparison process. In addition to the examples discussed in Section 3, we note that there are good opportunities to provide additional information to the brokers. For instance, a trade report that does not compare can be returned with the badge numbers and identities of other traders and brokers that had problem trades in that security that day. These are likely contraparty candidates for resolving uncompared trades, but are not known to the firms handling trade exceptions.

Brokers will benefit from the ability to add their own policies and rules to interpret and process clearinghouse messages. These rules can be used to handle some messages automatically (perhaps using in-house transaction processing data), to inform workers more thorough$\mathrm{ly}$, and even to initiate and conduct machine-to-machine dialog with other brokers.

Labor costs can be reduced, as fewer trades require manual exceptions processing, and when human intervention is required workers have more relevant information easily available.

The status of trades can be tracked, leading to better control over problem trades and financial exposure. With more expressive messaging, provisional or qualified trades (that may not eventually settle) can be highlighted in management accounting reports. Compared trades may be quickly identified and reported.

The system is upgradeable and robust to change. The representation scheme described can be integrated with other systems in the industry, including order routing and trading systems, and payment and funds transfer networks. Message formalization and use of a robust FLBC thus have positive externalities with other parts of the business. Finally, we note that these advantages considerable as they are in the present context are obtainable in many other situations in commerce.

\section{Prototype}

A Settlement prototype was developed on a Macintosh II CX using Claris HyperCard Version 2.1. In the prototype, there are four member firms (Merrill [MER], Goldman [GS], Salomon [SB], and Kidder [KP]) and a clearinghouse. A test script was created of 36 sides (18 trades); with each of the member firms making errors of various types in their submissions to the clearinghouse. For example, any one or more of the following might be in error in any given trade: the contra badge, or the trade time, the price, the quantity, etc. In the script some firms submitted imaginary trades (ones with no counterparty).

The sides are submitted to the clearinghouse, which orders them by trade time. The compare routine runs through the pooled sides, identifying the counterparty in the event of perfect matches or matches with one or more fields on the trade input record in disagreement. Its output is a stream of compare and miscompare messages.

Our current work is on inter-firm automated communications to resolve miscompared trades - e.g., price miscompares might be reconciled using inter-firm messages and machine reasoning. Figure 6 highlights the message received by Merrill (MER) after the clearinghouse comparison process.

\section{Conclusions}

A trade is an elaborate information event, which triggers a number of instructions and messages. In the absence of exceptions, the current message representations perform adequately. When exceptions occur because errors in the operations cycle lead to offsetting messages or confirmations not being received the trading parties undertake a costly manual procedure. Parkinson et al. (1992) noted in a Federal Reserve Staff Study that "Lack of coordination among clearing organizations can heighten credit and liquidity risk, [and] clearing organizations may not have enough information to evaluate the riskiness of a participant that is involved with other clearing organizations." The points we have made are a step toward improved coordination, and generalize nicely. To see this, recall Figures 2 and 3 . These figures lay out a ten-step process for after-trade processing. Eight of the steps involve inter-organizational communications. The discussion so far, and the implementation, have focused largely on just one of these steps, Step 4, in which the clearinghouse reports on the results of its efforts to compare the trades of the previous day. We have argued that, for Step 4, the benefits of an FLBC approach would be substantial. If there is advantage in moving to an FLBC in Step 4 - for which a fixed-field, record-passing scheme is already in use - then there is potentially much greater advantage in using an FLBC approach for those inter-organizational messages that are not now computerized at all, in particular, the broker-to-broker messages reconciling uncompared trades.

The underlying logical structure of the Step 4 messages is really quite simple; the clearinghouse reports 
that it does or does not have compared trades. In terms of speech act theory, the clearinghouse is merely making a series of interesting assertions, which the brokerage houses pay close attention to. Responding to these messages, however, is a complicated matter, calling for messages between brokerage houses. These messages, whether or not supported by formalization, are logically complex. In addition to other speech acts, brokers will make assertions (e.g., "We think we traded with your firm on this date"), ask questions (e.g., "Do you have anything that might match our uncompared trade?"), and offer proposals (e.g., "Since we differ only in price, and it's small, let's split the difference"). The current record passing scheme cannot hope to handle this complexity. An FLBC approach is virtually required if we are to bring automatation to these communications.

Just as there is a distinction between clearinghouse messages and messages between brokers, so there is a distinction of import between messages, which communicate meaning, and the reasoning that must be done about the messages. When the messages are formalized, it is possible to implement machine-based reasoning about them. This reasoning, moreover, is possible when an FLBC approach is taken. With a recursivelydefined language, it is easier and more natural to write general rules for handling messages - e.g., involving reasoning with time, defeasibility, and obligation. The details of this point are beyond the scope of this paper. The case we have made for the clearinghouse component of the problem is a necessary first step to exploiting the full value of an FLBC approach to the overall trade processing problem.

\section{References}

Clemons, E. and B. Weber, "Evaluating the Prospects for Alternative Electronic Securities Markets", Proceedings, 12th Annual International Conference on Information Systems, New York, NY, December 1991, pp. 53-63.

Lucas, H. Jr. and R. Schwartz (eds.), The Challenge of Information Technology for the Securities Markets: Liquidity, Volatility, and Global Trading, Dow Jones-Irwin, 1989.

\section{Figure 6: Prototype Screen}

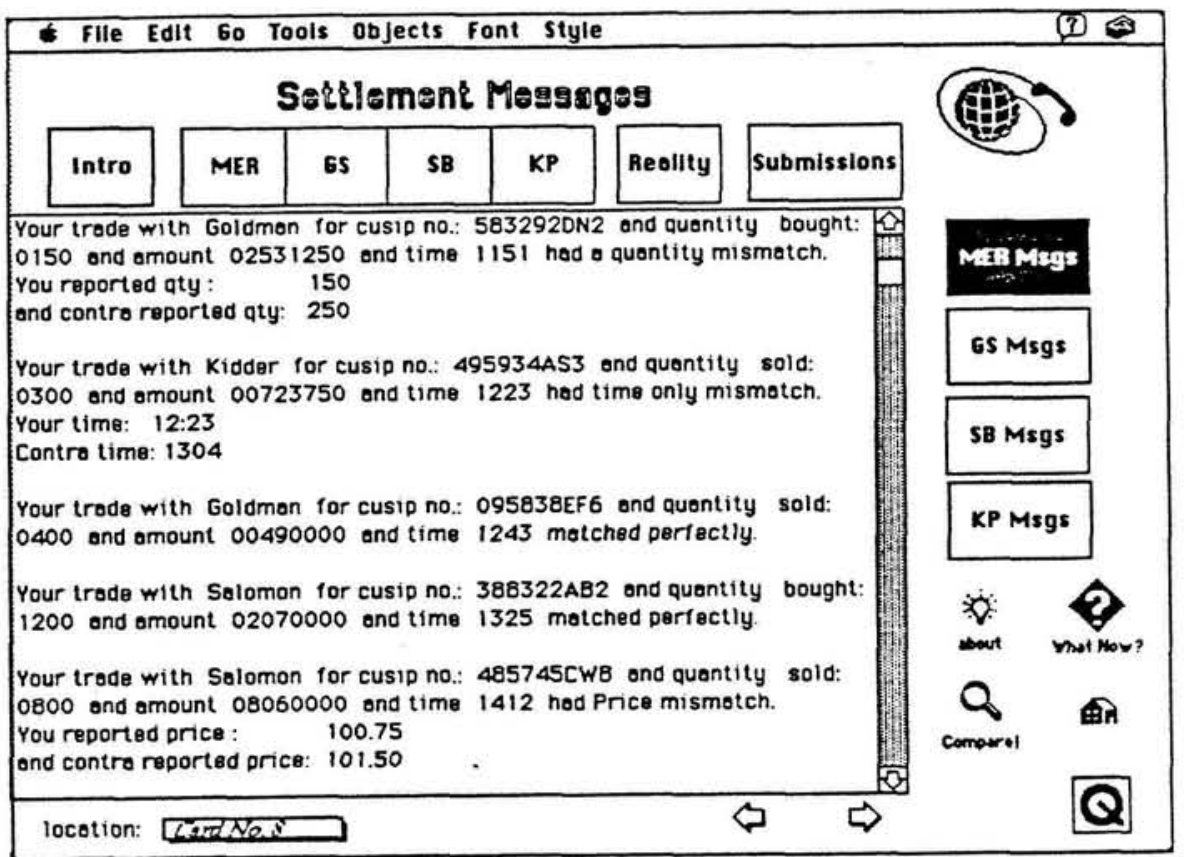

Kimbrough, S. and S. Moore, "On Obligation, Time, and Defeasibility in Systems for Electronic Commerce", Proceed ings, HICSS, 1993, pp. 493-502.

Kimbrough, S. and S. Moore, "Message Management Systems: Concepts, Motivations, and Strategic Effects", Jourmal of Management Information Systems, Fall 1992, pp. 29-52.

Kimbrough, S., and M. Thomburg, "On SemanticallyAccessible Messaging in an Office Environment", Proceedings, Twenty-Second Hawaii International Conference on Systems Sciences, January 1989.

Parkinson, P., A. Gilbert, E. Gollob, L. Hargraves, R. Mead, J. Stehm, and M. Taylor, "Clearance and Settlement in U.S. Securities Markets", Board of Governors of the Federal Reserve System, Washington, DC, March 1992.

Reddy, M.T. Securities Operations: A Guide to Operations and Information Systems in the Securities Industry, Simon \& Schuster, New York, 1990.

Stuchfield, N. and B. Weber, "Modeling the Profitability of Customer Relationships: Development and Impact of BZW's BEATRICE", Journal of Management Information Systems, Fall 1992, pp. 53-76.

Weiss, D.M. After the Trade is Made: Processing Securities Transactions, New York Institute of Finance, New York, 1986.

Weber, B. "Information Technology in the Major International Financial Markets", Forthcoming in: Global Information Systems and Technology: Focus on the Organization and its Functional Areas, P.C. Deans and K.R. Kewan (eds.), 1993. 